\title{
Seasonal succession patterns of plankton in eutrophic rivers on plains
}

\author{
Ning Chen, Ling Liu*, Danying Qiao, Yanfeng Li and Yiyan Lv \\ College of Hydrology and Water Resources, Hohai University, No. 1, Xikang Road, Gulou District, Nanjing 210098, China
}

Received 9 July 2015; Accepted 8 February 2016

\begin{abstract}
The typical annual circulation of phytoplankton in eutrophic rivers has been documented. However, there is still a conspicuous lack of consistency in subsequent reports. On the basis of an overall investigation of 15 eutrophic rivers on the Lower Yangze-Huai River Plain, the seasonal successions of phytoplankton according to morpho-functional groups (MFGs) were clustered. The results indicated fundamental agreement with the classic paradigm, but differences were found and tended to converge to at least three regular patterns. They were characterized respectively by: (1) winter peaks of large diatoms and a summer peak of cyanobacteria colonies, different zooplankton dominating alternately; (2) only a summer peak of bluegreen filaments, rotifers dominating all year round; and (3) composite peaks of filamentous cyanobacteria, centric diatoms and small flagellates, extremely low zooplankton density. All were potentially driven by anthropogenic influences through significantly changing water environments. Pattern 1 often developed in rivers with slow flow controlled by physicochemical factors, which was attributed to high levels of water retention. Pattern 2 often developed in rivers with massive suspended sediment controlled by hydrological features, which was attributed to massive shipping. Pattern 3 often developed in rivers with significant levels of organic pollutants controlled by dissolved oxygen, which were attributed to the agricultural load and overindustrialization. As a successful application of MFGs, we suggest that this type of morpho-functional approach for phytoplankton performed better in statistical analysis targeted to general ecological laws than to local details about just one specific water body, though this approach still needs to be improved.
\end{abstract}

Key words: Eutrophic plain rivers / plankton seasonal succession / anthropogenic influences / morpho-functional groups

\section{Introduction}

How eutrophication affects phytoplankton communities in lotic environments has been less frequently studied than in lakes and seas (Hilton et al., 2006), even though rivers have served human civilizations for millennia, besides the practical difficulties that arise for riverine systems (stochastic behavior, multiple organisms, several countries, limited access to background data, etc.) (Abonyi et al., 2012), another reason may be that it has been widely accepted and scarcely challenged that phytoplankton development is highly dependent on physical characteristics (light, water transparency and depth) rather than on nutrients (Wehr and Descy, 1998). However, analysis of long-term data shows that increases in algal biomass and changes in community structure in many rivers during recent decades may have resulted from increased nutrient inputs coupled with hydrological

\footnotetext{
*Corresponding author: lingliu504@163.com
}

changes and river regulation (Kiss, 1994; Hilton et al., 2006). Eutrophication of this type is more likely to occur in plain rivers.

The seasonal succession of phytoplankton under eutrophication is reasonably well understood in lakes (Salmaso et al., 2012), which are valuable references and sources of information for phytoplankton studies. Lentic water connected to rivers (lakes, reservoirs, backwater, side-arms and dead zones) is an important source of algal inocula to rivers, but phytoplankton are also "native" to rivers (Wehr and Descy, 1998). Furthermore, seasonal changes in the abundance, composition and dominance of phytoplankton relate to networks of interactions among physical, chemical, biological and longitudinal processes of river ecosystems and their watersheds, which reach a higher degree of complexity downstream (Wehr and Descy, 1998). This means that far more elements are added to community-driven processes (nutrient competition, grazer regulation and autogenic succession) argued to apply to lentic plankton. Also, most plain rivers are 
substantially altered by human activities (Sparks, 1995) that affect not only riverine organisms and processes, but also the links between a river and its floodplain (Townsend, 1996). Perhaps these are some of the reasons why models or theories (Sommer et al., 1986) for lakes are not applicable to predict phytoplankton production or species composition in most rivers.

Gamier et al. (1995) documented the seasonal succession of phytoplankton in lotic waters based on the Seine River system (France), which was characterized by high nutrient-enrichment, creating a paradigm for eutrophic rivers. In their study, towards the end of winter, diatoms were found to develop a spring bloom. As a consequence of grazing and infection, diatoms decreased rapidly in late spring. From the beginning of summer, phytoplankton were characterized by a mixed high population of Chlorophyceae, oscillations and diatoms. In autumn, decreasing light and temperature resulted in a decline in phytoplankton biomass toward a winter minimum. Due to hydrological factors (discharge, residence time, flow impulse), physical factors (light, temperature), nutrients (especially silica), and biotic factors (grazing of zooplankton and infection by viruses, bacteria, and fungi) in rivers, the successional sequence of phytoplankton tended to converge to a complex set of feedback mechanisms in shallow, intermittently stratified lakes, which are frequently interrupted by wind effects (Gamier et al., 1995). This study explained the key parts and typical features of complex eutrophication in dynamic riverine ecosystems, which has proven to be of great significance by many river ecologists (Garnier et al., 2002, 2005; Billen et al., 2005).

However, there are still conspicuous inconsistencies between data in an increasing number of reports concerning eutrophic rivers and the classic paradigm by Gamier et al. (1995). (1) Flagellates like Cryptophyta contribute significantly to phytoplankton biomass during transitional stages (de Oliveira and Calheiros, 2000; Mihaljević et al., 2013), while Gamier et al. (1995) did not mention them. (2) Cyanophyta are important in summer blooms, and they usually appear morphologically in filaments (e.g., Aphanizomenon, Baker and Baker, 1981) and colonies (e.g., Microcystis, Ha et al., 2002), while Gamier et al. (1995) only emphasized the former. (3) Sometimes diatom blooms occur in winter (Ha et al., 1998) while winter was classically considered as the season of minimum biomass. These phenomena must indicate the existence of different patterns of phytoplankton seasonal succession in eutrophic rivers, involving some yet unknown or neglected regulations of nature. Physical factors, along with nutrients, biotic interactions, watershed processes and human interference also influence community composition, but we are a long way from being able to identify which are the most important determinants at the species level. Even at the level of major taxonomic groups, only basic trends can be identified (Wehr and Descy, 1998). Fortunately, the morpho-functional approach stands out as the best surrogate of traditional taxonomy.

The morpho-functional groups (MFG, Salmaso and Padisák, 2007), theoretically based on phytosociology, integrate the most important morphological and functional features of phytoplankton proposed by Weithoff (2003), which include motility, the potential capacity to obtain carbon and nutrients by mixotrophy, specific nutrient requirements, size and shape, and presence of gelatinous envelopes. Other functional classifications either require deeper functional knowledge of the taxonomy (functional groups, FG, Reynolds, 1998) or depend purely on morphological traits leading to low sensitivity (morphologically based functional groups, MBFG, Kruk et al., 2010). The advantages and limitations of the MFGs are modest, and the MFGs have provided valuable information about seasonal dynamics and the hydrological regime in lakes (Tolotti et al., 2010) and river-floodplains (Mihaljević et al., 2013). We therefore considered MFGs as a potentially suitable tool for investigating and comparing phytoplankton assemblages in eutrophic rivers.

Research combining phytoplankton and zooplankton in multifarious rivers is still lacking. This study was conducted in 15 eutrophic rivers on the Lower YangzeHuai River Plain, investigating phytoplankton and zooplankton, as well as physicochemical and hydrological aspects. The rivers offer different conditions for phytoplankton development. We hypothesized that similarities among MFGs will arise in analogous conditions, while quite different patterns of MFGs will develop in distinct conditions. The study objectives were to:

(1) Determine what patterns of phytoplankton seasonal succession typically occur in eutrophic plain rivers and which key factors shape them;

(2) Discuss the main anthropogenic influences on phytoplankton community changes;

(3) Test whether MFG is useful as a tool in explaining eutrophication processes of riverine systems.

\section{Materials and methods}

\section{Sampling and measurements}

Sampling was performed monthly during the year of 2013 (January-December) at 39 sampling sites of the 15 eutrophic rivers, located on the Lower Yangze-Huai River Plain (117.41-121.94 E, 30.09-33.06 ${ }^{\circ} \mathrm{N}$ ), southeast China. The plain belongs to the monsoonal transitional area from the temperate to subtropical zones and the mean annual precipitation is about $1000 \mathrm{~mm}$. This is one of the most densely populated and rapidly developing regions in Asia with anthropogenic impacts that have spread to every inch of the river system. Water eutrophication has become a major problem. Our study was conducted on the rivers that play important roles in both ecological and socioeconomic systems. Additional information on sampling rivers and sites is shown in Figure 1 and Table 1.

Depth $(\mathrm{D}, \mathrm{m})$, surface water temperature $\left(\mathrm{WT},{ }^{\circ} \mathrm{C}\right)$, $\mathrm{pH}$, Chlorophyll- $a\left(\right.$ Chl- $\left.a, \mu \mathrm{g} . \mathrm{L}^{-1}\right)$ and dissolved oxygen (DO, mg. $\mathrm{L}^{-1}$ ) were measured using portable instruments, YSI model 55 probe (Yellow Springs Institute, USA) 


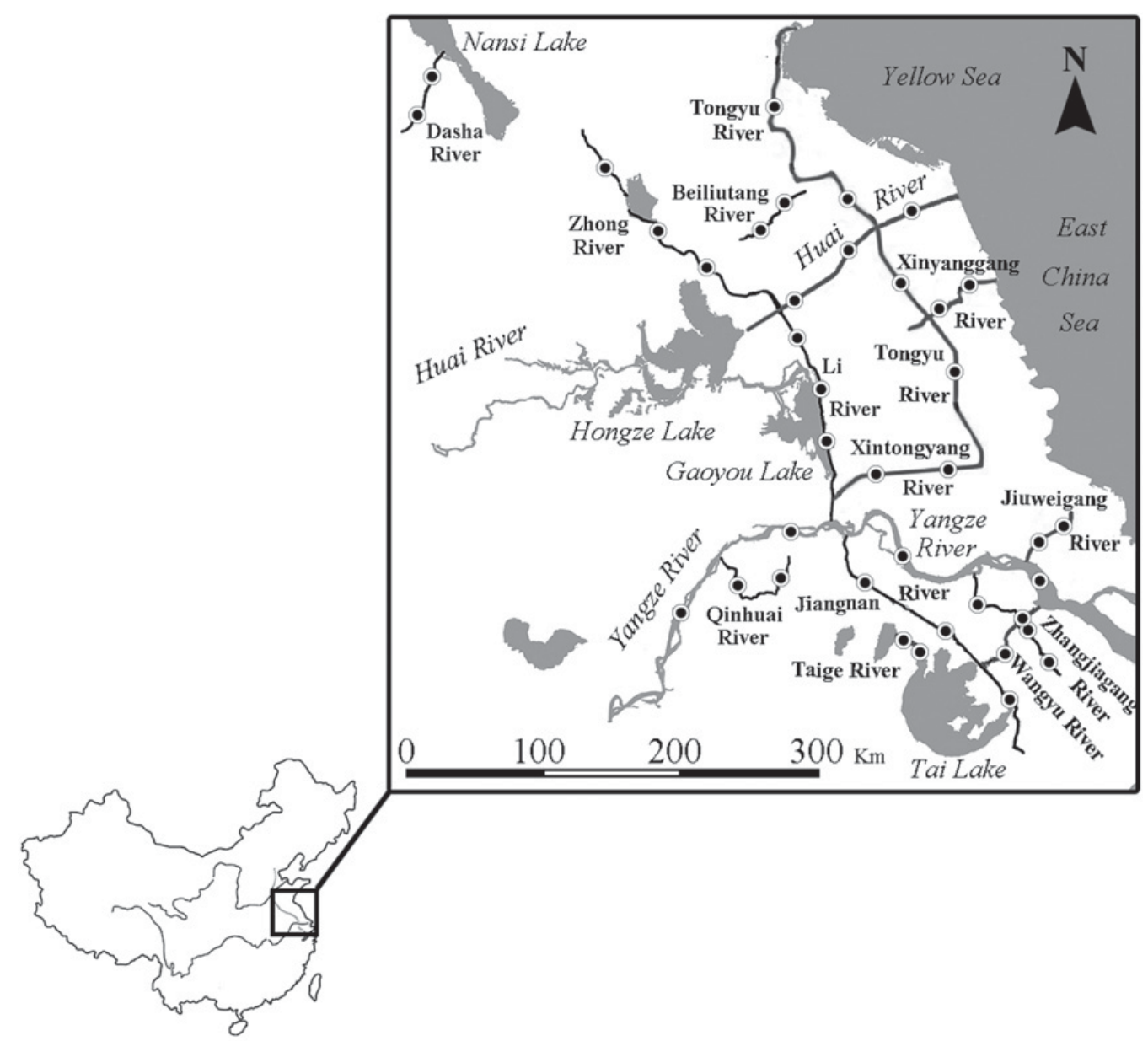

Fig. 1. Study area with the sampling sites indicated.

Table 1. Geological and hydrological properties of study reaches.

\begin{tabular}{|c|c|c|c|c|c|c|c|}
\hline \multirow[b]{2}{*}{ Rivers } & \multirow[b]{2}{*}{ Code } & \multirow{2}{*}{$\begin{array}{c}\text { Length } \\
(\mathrm{km})\end{array}$} & \multirow{2}{*}{$\underset{\left(\mathrm{km}^{2}\right)}{\text { Drainage area }}$} & \multicolumn{3}{|c|}{ Investigated reaches } & \multirow[b]{2}{*}{ Number of samples } \\
\hline & & & & North latitude & East longitude & Altitude (m) & \\
\hline Beiliutang river & BLT & 62.5 & 1512 & $34.142-34.274$ & $118.573-119.544$ & $2.10-11.10$ & 2 \\
\hline Dasha river & DS & 59.2 & 1695 & $34.574-34.768$ & 115.861-116.762 & $35.33-53.40$ & 2 \\
\hline Huai river & HR & 1000.2 & 270562 & $33.139-33.884$ & $119.169-120.263$ & $0.61-5.42$ & 3 \\
\hline Jiangnan river & $\mathrm{JN}$ & 211.7 & 3406 & $31.231-32.037$ & $119.584-120.688$ & $5.00-14.90$ & 3 \\
\hline Jiuweigang river & JWG & 46.3 & 1317 & $32.084-32.278$ & $120.767-121.097$ & $3.53-5.45$ & 2 \\
\hline $\mathrm{Li}$ river & LR & 208.7 & 5094 & $32.411-33.546$ & $119.107-119.517$ & $6.64-8.24$ & 3 \\
\hline Qinhuai river & QH & 51.9 & 1525 & $31.941-31.969$ & $118.690-119.132$ & $3.91-13.49$ & 2 \\
\hline Taige river & $\mathrm{TG}$ & 22.1 & 431 & $31.491-31.595$ & $119.885-120.037$ & $6.85-46.68$ & 2 \\
\hline Tongyu river & TY & 368.1 & 7051 & $32.872-34.458$ & $119.196-120.334$ & $2.00-3.30$ & 4 \\
\hline Wangyu river & WY & 60.3 & 1489 & $31.458-31.755$ & $120.481-120.791$ & $5.21-7.77$ & 2 \\
\hline Xintongyang river & XTY & 90.2 & 2504 & $32.461-32.508$ & $119.558-120.614$ & $2.62-8.70$ & 2 \\
\hline Xinyanggang river & XYG & 94.4 & 2219 & $33.362-33.631$ & $120.057-120.519$ & $0.00-1.00$ & 2 \\
\hline Yangze river & $\mathrm{YZ}$ & 6280.3 & 1807273 & $31.913-32.273$ & $118.576-120.867$ & $0.00-22.55$ & 4 \\
\hline Zhangjiagang river & ZJG & 106.9 & 1487 & $31.616-31.880$ & $120.423-120.863$ & $1.11-4.12$ & 3 \\
\hline Zhong river & ZR & 165.8 & 6057 & $33.602-34.345$ & $117.938-118.784$ & $12.59-24.77$ & 3 \\
\hline
\end{tabular}

in situ. The light attenuation coefficient $\left(K_{\mathrm{d}}, \mathrm{m}^{-1}\right)$ was calculated from irradiance by a spectrum-submersible radiometer (SR9910-PC) (Kirk, 1994). Water velocity $\left(\mathrm{V}, \mathrm{m} . \mathrm{s}^{-1}\right)$ was measured using a portable flow meter LS300-A. Discharge $\left(\mathrm{Q}, \mathrm{m}^{3} \cdot \mathrm{s}^{-1}\right)$ was represented by the mean monthly value from the nearest hydrological station.
In the laboratory, total nitrogen $\left(\mathrm{TN}, \mathrm{mg} . \mathrm{L}^{-1}\right)$ and total phosphorus (TP, mg. $\mathrm{L}^{-1}$ ) were measured with a flow injection analyzer (Skalar $\mathrm{SAN}++$, Netherlands). Soluble reactive silicate $\left(\mathrm{RSi}, \mathrm{mg}^{-\mathrm{L}^{-1}}\right.$ ) was measured by plasma emission chromatography ICAP (ICP6300, USA). Suspended sediment concentrations (SSC, mg. $\mathrm{L}^{-1}$ ) of 
surface water were determined by water sample filtration $(0.45 \mu \mathrm{m})$ through porcelain filters and dried at $105^{\circ} \mathrm{C}$ to constant weight measured with an electronic balance (Mettler ME104E, Switzerland). The information about land use, water facilities and navigation capacity were collected from the China Statistical Yearbook 2013 and a field survey.

Subsurface phytoplankton samples were fixed in situ with Lugol's solution. Algae counts for density calculations were performed using an inverted microscope (OLYMPUS IX-70) following the Utermöhl method (Lund et al., 1958) at $\times 400$ magnification and the counting error was estimated according to Duarte et al. (1990). At least 400 units (cells, filaments and colonies) for each sample were enumerated and cell numbers per colony or filament were estimated. Biovolumes were calculated according to Hillebrand et al. (1999). Phytoplankton biomass (mg. $\mathrm{L}^{-1}$ ) was obtained from conversion of biovolume following Hasle and Sournia (1978) and Javornicky and Komárková (1973).

Zooplankton were collected using a $30-\mathrm{cm}$ diameter plankton net $(64-\mu \mathrm{m}$ mesh) and fixed with buffered formaldehyde ( $10 \%$ final concentration). The total volume of river water filtered was measured by a flow meter placed next to the mouth of the net. The fixed sample was concentrated and re-suspended in filtered river water up to $30 \mathrm{~mL}$ volume before microscopic analysis. Individuals were enumerated and identified to genus level using an upright microscope (OLYMPUS BX-51). In this way, we were able to calculate the density (ind. $\mathrm{L}^{-1}$ ) of samples.

\section{Data analysis}

The clustering technique (average linkage) was used to hierarchize the river samples of phytoplankton based on similarity in annual series of (1) genera, (2) classes and (3) MFG biomass represented by a dendrogram. The BrayCurtis' similarity was calculated after square root transformation.

To compare the phytoplankton assemblages in the different clusters, we used non-metric multi-dimensional scaling (NMDS), employing Euclidean distance. This nonparametric ordination technique provided a visual representation of dissimilarity distances of sampling sites. Significant differences among physicochemical metrics and human effects for patterns were determined using analysis of variance (ANOVA). All analyses were performed using the statistical program PRIMER, version 5.0 (Clarke and Warwick, 2001) and SPSS 19.0.

To determine the leading environmental factors and the threshold values of different patterns, a classification and regression tree was used. This tree was constructed by recursive binary partitioning of the response variable into regions that are increasingly homogeneous (i.e., nodes) until no improvement was possible (Kruk and Segura, 2012). It was pruned back to avoid overfitting by minimizing the cross-validated error after construction (De'ath and Fabricius, 2000).
To assess the relationship between MFGs and the measured environmental variables, redundancy analysis (RDA) was applied after detrended correspondence analysis (DCA) determined that the linear statistical technique would be most appropriate (Lepš and Šmilauer, 2003). The biomass data were log-transformed to meet the normality requirements. DCA and RDA were performed with CANOCO for Windows, version 5.0.

\section{Results}

\section{The patterns of plankton seasonal succession}

A total of 235 algal taxa belonging to 26 MFGs (Table 2), 26 zooplankton genera consisting of 3 copepods, 11 cladocera and 12 rotifera were identified in the 468 river samples during 2013 (see Appendix). Although it failed on phytoplankton taxa analysis of genus and class level, the hierarchical clustering and NMDS succeeded in showing the affinities between study sites when considering the annual series of MFG biomass (Figs. 2 and 3).

The highest hierarchical level shows a separation of four rivers (DS, QH, WY and TG) marked as Pattern 1 (Fig. 4(a)): Large diatoms (6a-LargCent and 6b-LargPenn) often peaked during the cold 6 months when rotifers dominated; Cyanobacteria colonies (5b-LargVanC, 5c-LargChro and 5d-SmalChro) peaked in summer when copepods and cladocera dominated. Accordingly, the second largest group comprised 11 rivers, which were divided at the Bray-Curtis similarity level of approximately $55 \%$ into two subgroups. Both subgroups were characterized by cyanobacteria filaments (5a-FilaCyan and 5e-Nostocales). One group containing samples from seven rivers (HR, JN, LR, TY, XTY, YZ and ZR) was marked as Pattern 2 (Fig. 4(b)): Blue-green filaments (5a-FilaCyan, 5e-Nostocales and 10a-FilaChlo) peaked in summer; copepods increased during warm seasons; low biomass occupied other months and small diatoms (7a-SmalCent and 7b-SmalPenn) and rotifers made a significant contribution all year. The other subgroup containing samples from four rivers (BLT, JWG, XYG and ZJG) was marked as Pattern 3 (Fig. 4(c)): centric diatoms (6a-LargCent and 7a-SmalCent) peaked in the cold half of the year; filamentous cyanobacteria (5a-FilaCyan and 5e-Nostocales) peaked in summer; small flagellates (2c-SmalEugl and 2d-Crypto) grew in warm seasons. Zooplankton were extremely low in abundance (mean 56.4 ind. $\mathrm{L}^{-1}$ ) and in diversity (almost only rotifers), indicating a very limited grazing effect.

\section{Anthropogenic influences and environmental variables}

Considerable human activities including water retention, navigation and land use seemed to closely correlate with the three patterns of phytoplankton seasonal succession (Fig. 5). Eutrophic rivers of Pattern 1 possessed the 
Table 2. List of the morpho-functional groups (MFGs) according to Salmaso and Padisák (2007) and modified by Tolotti et al. (2012) contributing more than 5\% to the total potamoplankton biomass recorded in the eutrophic rivers on the Lower Yangze-Huai Plain in 2013.

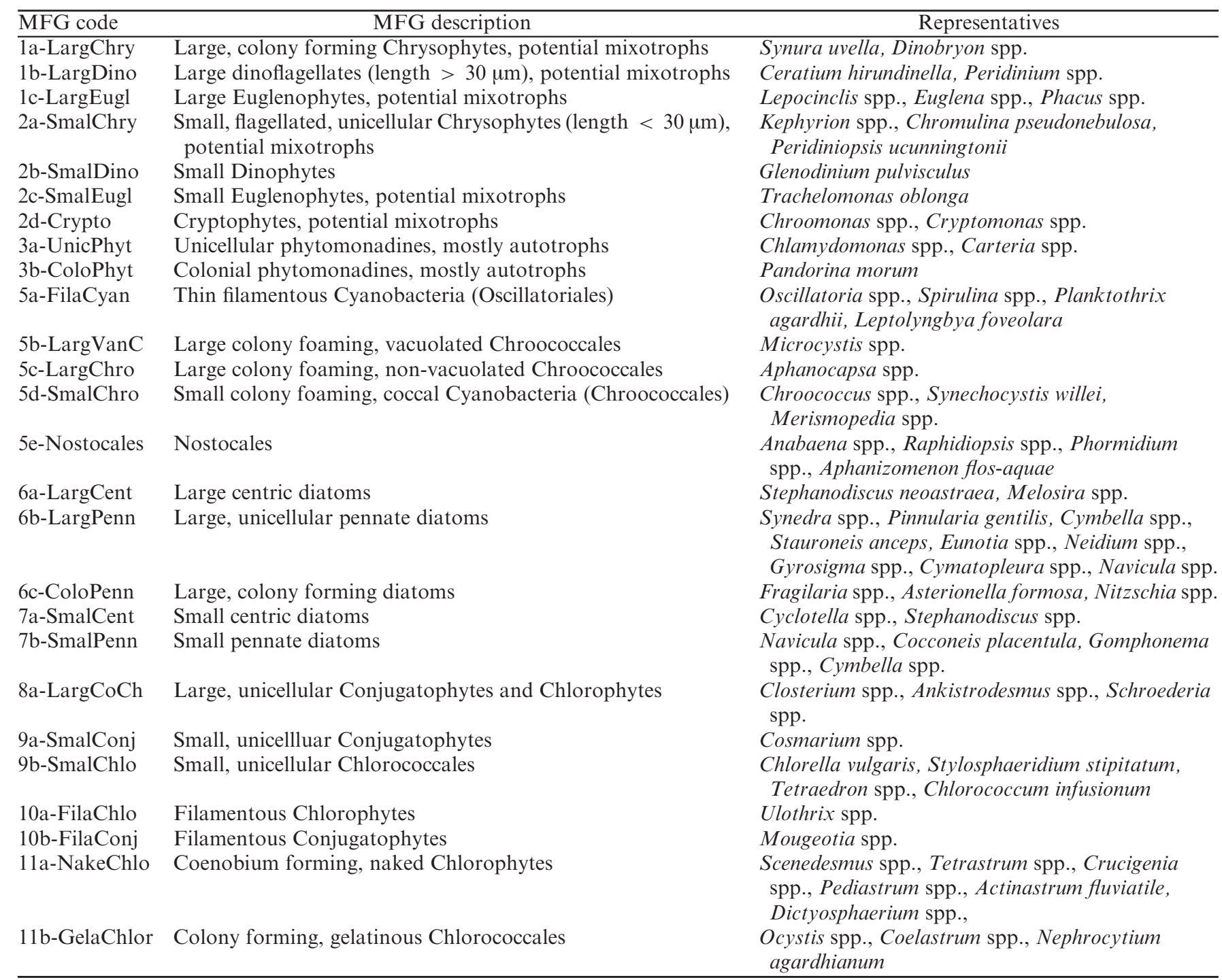

greatest density of water retention facilities (mean 5.6 facilities per $\mathrm{km}$, ANOVA $P<0.05)$. The rivers of Pattern 2 had the highest navigation capacity (mean $>1000 \mathrm{t}$, ANOVA $P<0.05$ ). Lastly, the rivers of Pattern 3 were $100 \%$ (ANOVA $P<0.01$ ) surrounded by human-used land.

Also, rivers clustered by the three patterns were adequately discriminated according to the environmental variables by the tree (Fig. 6). V was the first selected variable with a threshold value of $0.5 \mathrm{~m} . \mathrm{s}^{-1}$ in the first node, the root node. The next selected variable was SSC with threshold values of $60 \mathrm{mg} . \mathrm{L}^{-1}$. The further selected variable was chemical oxygen demand (COD) whose threshold value was $15 \mathrm{mg}^{-\mathrm{L}^{-1}}$. As a result, the driving environmental conditions of each pattern could be described as: Pattern 1 developed in $V<0.5 \mathrm{~m} . \mathrm{s}^{-1}$; Pattern 2 developed in $V>0.5 \mathrm{~m} . \mathrm{s}^{-1}$, and SSC $>60 \mathrm{mg} . \mathrm{L}^{-1}$; and
Pattern 3 developed in $V>0.5 \mathrm{~m} . \mathrm{s}^{-1}, \mathrm{SSC}<60$ and $\mathrm{COD}>15 \mathrm{mg} \cdot \mathrm{L}^{-1}$.

The parameter details of the rivers from different patterns are shown in Figure 7. In addition, Pattern 2 rivers were characterized by low Chl- $a$ (mean $6.5 \mu \mathrm{g} . \mathrm{L}^{-1}$, ANOVA $P<0.05)$ and high $K_{\mathrm{d}}$ (mean $5.8 \mathrm{~m}^{-1}$, ANOVA $P<0.01)$. Pattern 3 rivers were characterized by low DO (mean $6 \mathrm{mg} . \mathrm{L}^{-1}$, ANOVA $P<0.05$ ) and high TN (mean $3.6 \mathrm{mg} . \mathrm{L}^{-1}$, ANOVA $\left.P<0.05\right)$. Other parameters such as WT, pH, TP and RSi showed no significant differences (Table 3).

\section{MFGs and environmental variables}

RDA analysis made it possible to evaluate the influence of significant environmental variables on MFG biomass in 


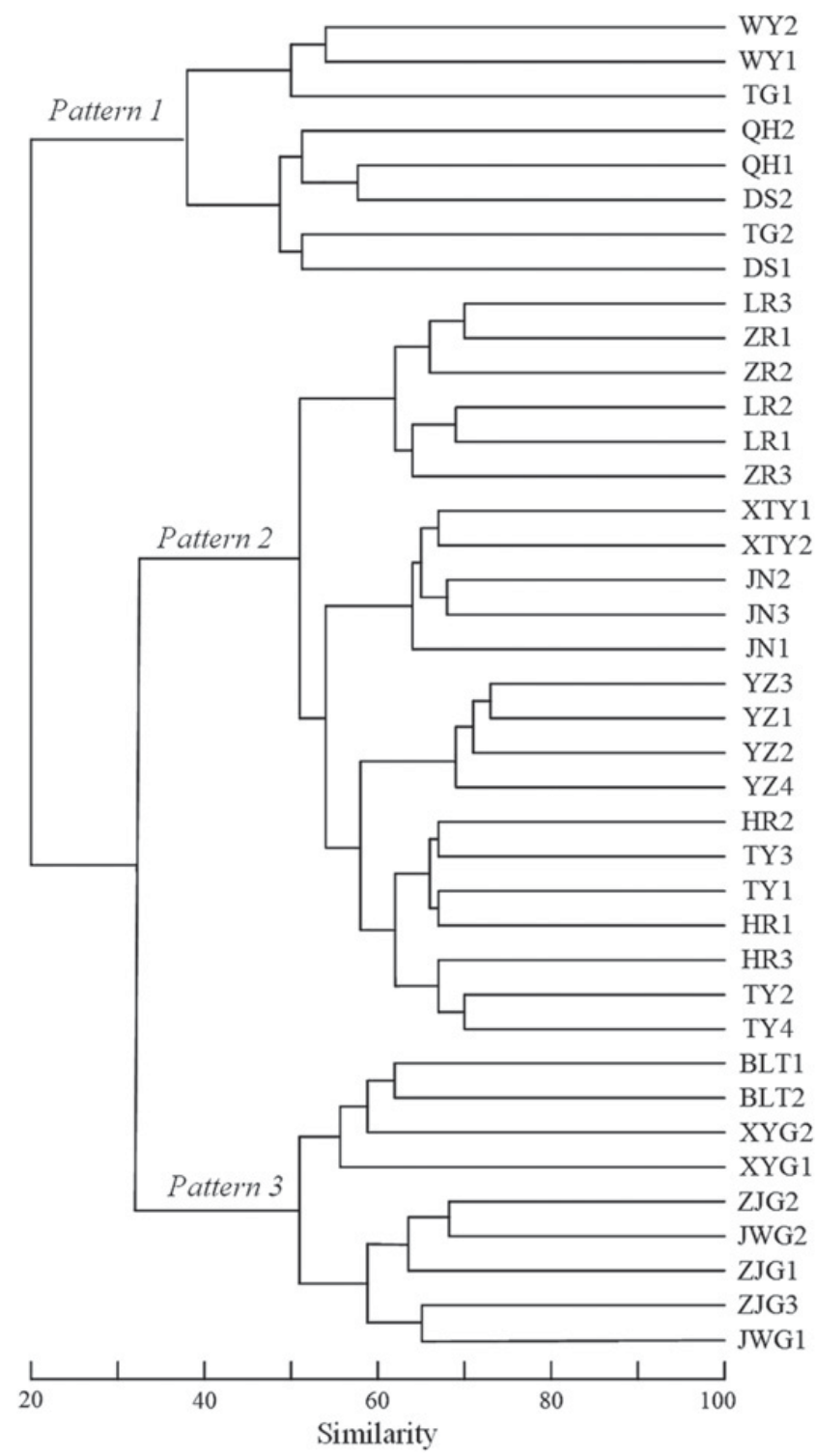

Fig. 2. Hierarchical dendrogram showing group average clustering of Bray-Curtis indices of similarity based on annual series of MFG biomass data at all sampling sites from January to December 2013. For river codes, see Table 1.

Abbreviation: MFG, morpho-functional group.

different patterns of phytoplankton seasonal succession (Fig. 8).

In the RDA based on MFG biomass of Pattern 1 (Fig. 8(a)), the first two axes accounted for $69.9 \%$ of the variance (axis 1: $38.6 \%$; axis 2: $31.3 \%$ ). The Monte Carlo test indicated that the environmental variables were significantly correlated with the first axis $(P=0.010)$ and the test of significance of all canonical axes was also significant $(P=0.004)$. The first axis was mainly correlated with $\mathrm{pH}$ and $K_{\mathrm{d}}$ (intra-set correlation coefficients: 0.69 and -0.40 , respectively), and the second axis was mainly defined by WT (intra-set correlation coefficient: -0.59 ).

The results of the RDA based on MFG biomass of Pattern 2 are shown in Figure 8(b). In this case, the total

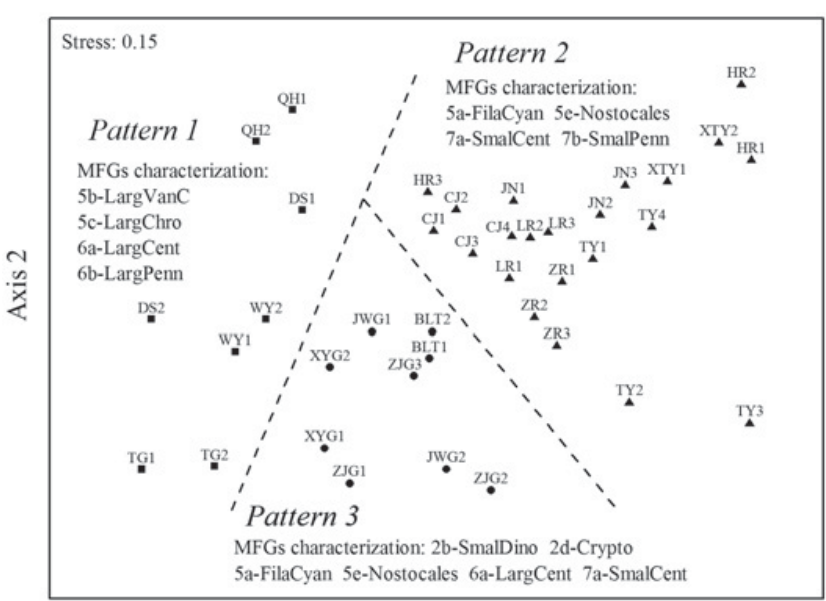

Axis 1

Fig. 3. NMDS ordination of all samples using annual series of MFG biomass data. Circles, triangles and squares indicate samples belonging to Pattern 1, Pattern 2 and Pattern 3, respectively. For river codes, see Table 1. For MFG characterization, see Table 2.

Abbreviations: NMDS, non-metric multi-dimensional scaling; MFG, morpho-functional group.

variance explained by the first two axes was $72.2 \%$ (axis 1 : $41.2 \%$; axis $2: 31.0 \%$ ). The environmental variables were significantly correlated with the first axis $(P=0.012)$ and the test for all canonical axes was also significant $(P=0.002)$. In this analysis, the first axis was also mainly defined by a combination of WT and Q (intra-set correlation coefficients: 0.35 and 0.30 , respectively), and the second axis by $K_{\mathrm{d}}$ (intra-set correlation coefficient: $-0.38)$.

In the case of the RDA carried out with MFG biomass of Pattern 3 (Fig. 8(c)), the percentage of explained variance was $74.1 \%$ (axis 1: $42.3 \%$; axis 2 : $31.8 \%$ ). The biplots corresponding to this analysis are shown in Figure 7(c). The Monte Carlo test was significant for the first axis $(P=0.010)$ and for all canonical axes $(P=0.006)$. The first axis was correlated with WT (intra-set correlation coefficients: 0.36), whereas the second axis was mainly defined by DO and $K_{\mathrm{d}}$ (intra-set correlation coefficients: 0.49 and -0.46 , respectively).

\section{Discussion}

\section{Anthropogenic influences}

The phytoplankton seasonal successions in the studied eutrophic rivers on a plain generally coincided with the paradigm of Gamier et al. (1995). However, based on the analysis of MFGs, succession divergences were found among distinct environmental conditions, which led to at least three regular patterns (Figs. 2-4) rather than random development. Compared with density in lakes, zooplankton were not as abundant probably due to dilution and washout, and nutrients (TP, TN and RSi) were not as 

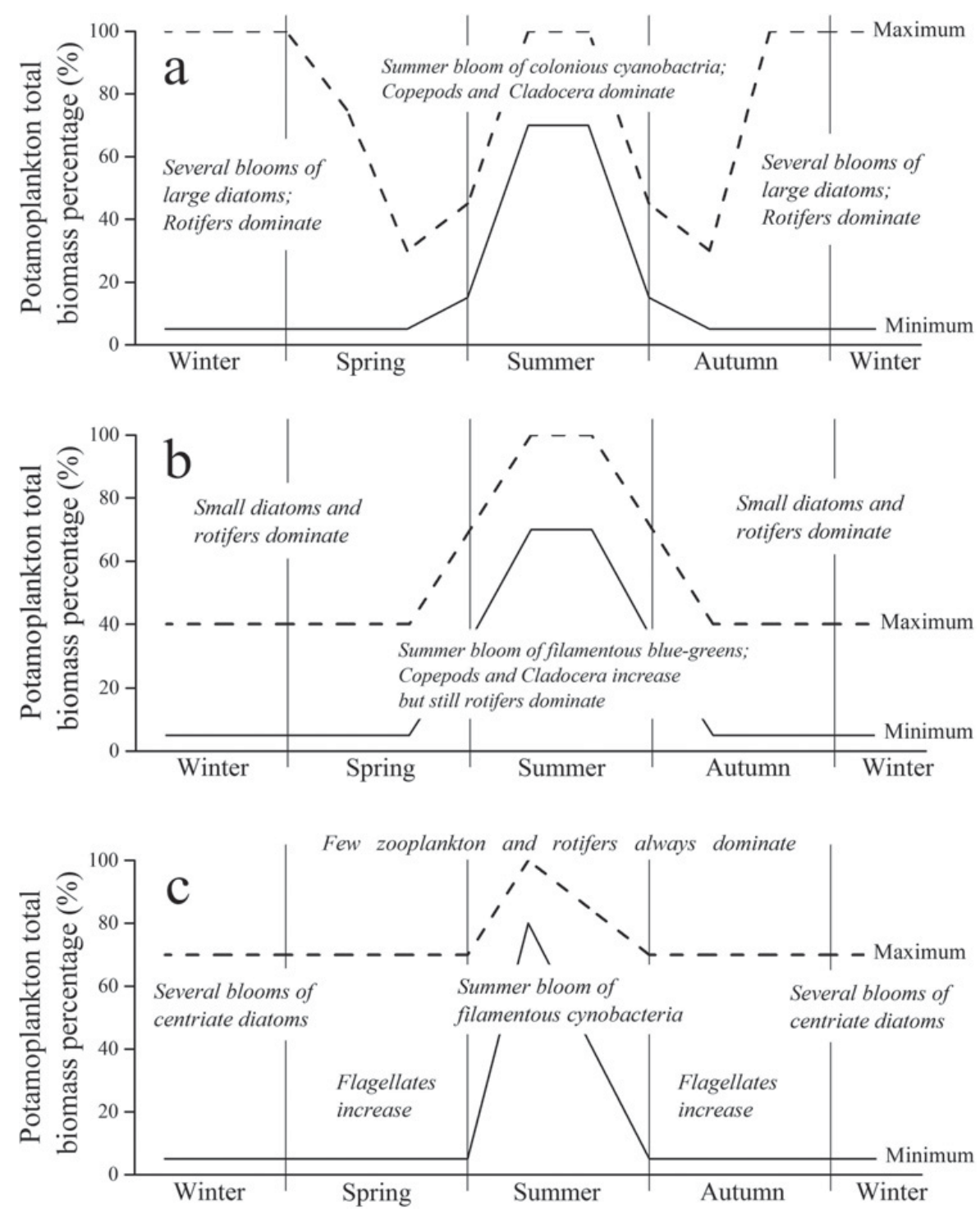

Fig. 4. The patterns abstracted from annual changes in biomass and share of dominant MFGs as well as zooplankton succession in studied rivers: Pattern 1 (a), Pattern 2 (b) and Pattern 3 (c). The dash line and the solid line represent the maximum and minimum of the possible biomass proportion, respectively.

Abbreviation: MFGs, morpho-functional groups.

important probably due to the eutrophic background. Thus, it is difficult for populations to be constrained by "top-down" or "bottom-up" controls. Many environmental factors varied (Fig. 7); however, water flow, suspended sediments and organic pollutants were shown to jointly control the development of phytoplankton (Fig. 6). We found that they corresponded to different anthropogenic influences and properties of flowing water.

Eutrophic rivers of Pattern 1 were characterized most densely by water retention facilities (Fig. 8(a)), which significantly prolonged the residence time and resulted in a serious risk of colonial cyanobacteria blooms (Ha et al., 2002). The rivers of Pattern 2 were all important channels for water transportation (Fig. 8(b)). Continual shipping increased the suspended sediment concentration due to boat traffic movements, distinctly influencing patterns of bed sediment resuspension and hence turbidity (Garrad and Hey, 1987). Pattern 3 succession in the organic contaminant rivers might be the consequence of non-point source pollution and sewage-effluent interference, since such rivers were surrounded by land for agriculture, industry and urbanization (Fig. 8(c)). It has been unanimously recognized that the use and management of watersheds are deeply connected to water ecosystems (Salmaso et al., 2012).

Below we describe in detail how specific factors shaped the three patterns that were reflected by the morphological characteristics of phytoplankton.

\section{Pattern 1}

Pattern 1 is shaped by water retention facilities. There were the most occurrences of lacustrine elements in 

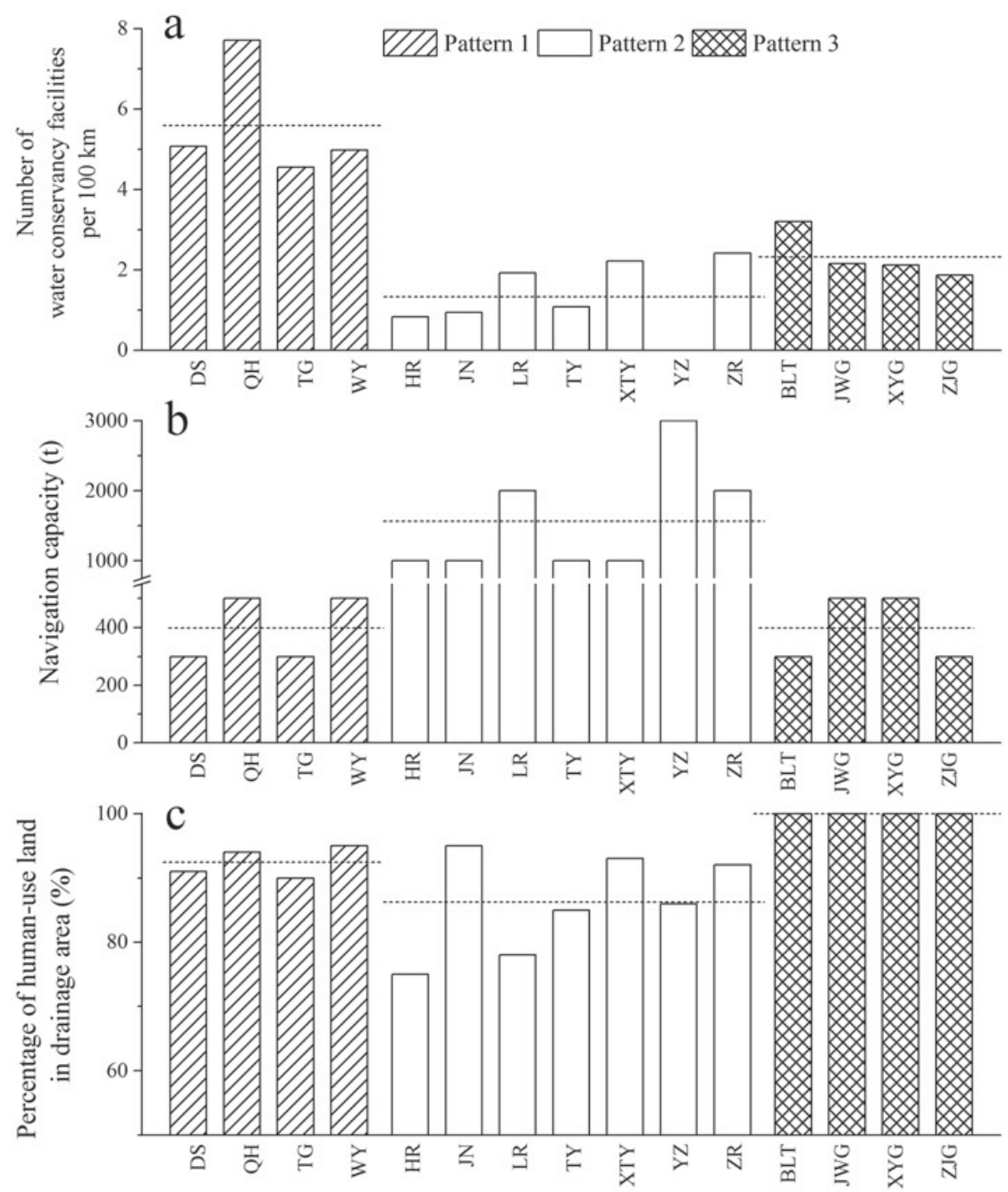

Fig. 5. Columns comparing anthropogenic influences on the rivers of the three patterns: (a) dense water retention facilities, (b) navigation capacity and (c) proportion of human-use land. The dotted line represents the mean value of each pattern.

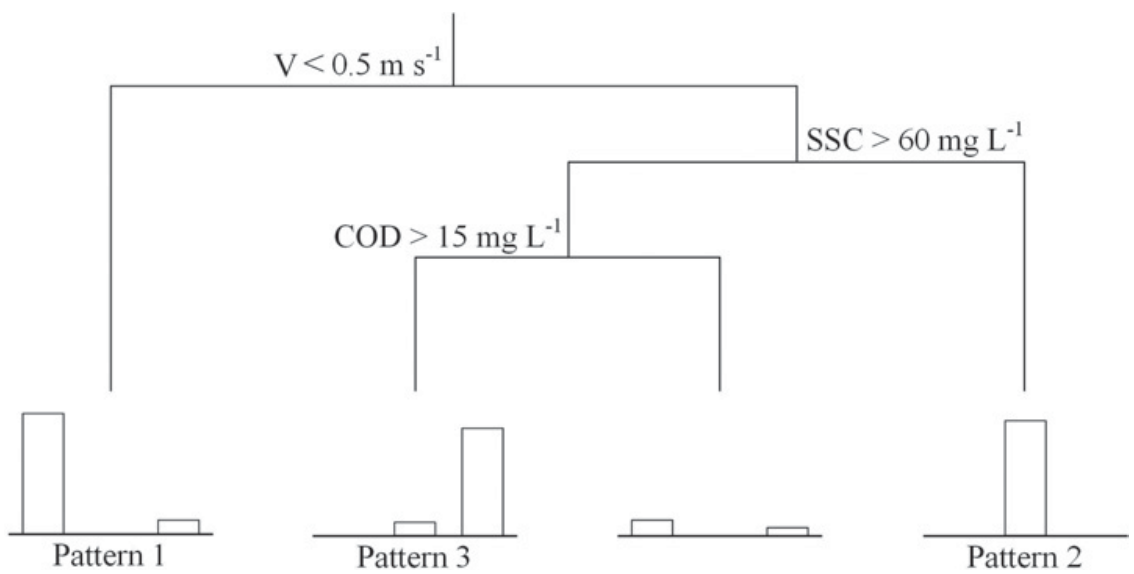

Fig. 6. Classification tree showing the environmental variables shaping the patterns of phytoplankton seasonal succession. In each node, the environmental variable and its threshold value are shown. Flow velocity (V), SSC and COD. At the end of each branch, a histogram with bars represents the number of sites belonging to a specific pattern (Patterns 1-3: left-right). The pattern with more sites is shown below each histogram.

Abbreviations: COD, chemical oxygen demand; SSC, suspended sediment concentration. 

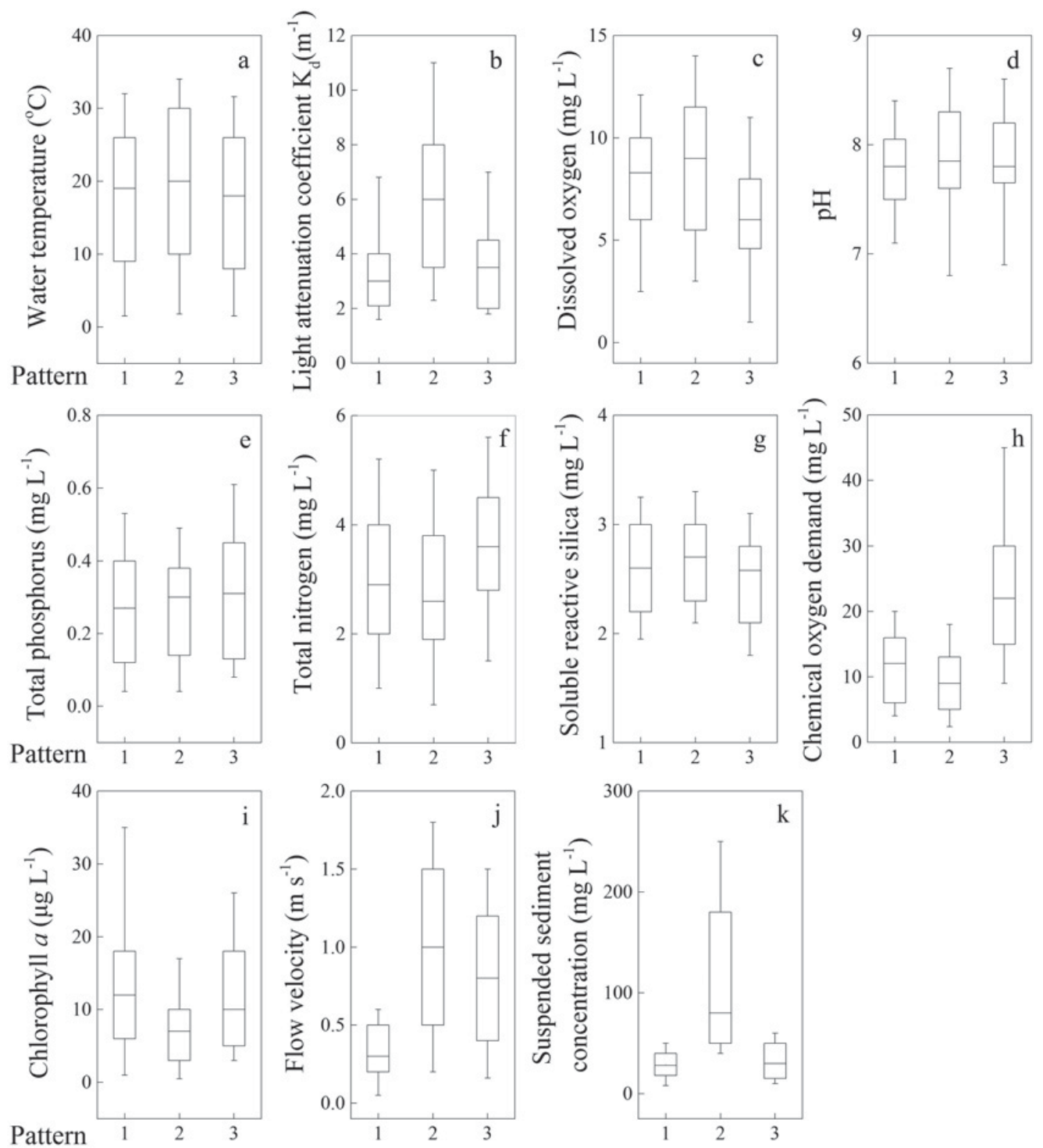

Fig. 7. Box-plots representing variations in water temperature (a), light attenuation coefficient (b), dissolved oxygen (c), pH (d), total phosphorus (e), total nitrogen (f), soluble reactive silica (g), chemical oxygen demand (h), chlorophyll a (i), flow velocity (j) and suspended sediment concentration $(\mathrm{k})$ in the rivers of the three patterns during the research period (January-December 2013). The bottom and top of each box represent the 25 and $75 \%$ quartile, respectively, and the short line in the box represents the median. The upper and lower tails indicate the range of the values.

Pattern 1, which was even characterized by eutrophic, epilimnetic Cyanobacteria colonies (5b-LargVanC, $5 \mathrm{c}$-LargChro and 5d-SmalChro) resulting in lake-type equilibrium assemblages (Naselli-Flores et al., 2003) during the warm season. The various water retention facilities concentrated along these rivers modified the flow regime, water residence time, nutrient distributions and light conditions, and therefore the seasonal succession of phytoplankton and species distribution (Palau, 2006). At many times, most rivers typify the plankton assemblages to a weak, colonist community organization of primitive, pioneer successional stages (high productivity, free nutrients, weak trophic connections and low interspecific competition) (Reynolds and Descy, 1996). However, the prolonged residence time of Pattern 1 rivers provided a relatively stable habitat at least for a period of time. It was adequate to lead to large populations, more bioticallymediated, community-driven selection and the advance of true ecological succession. Consequently, in the rich and warm season, large zooplankton (copepods and cladocera) had the opportunity to develop and dominate. Nevertheless, it was difficult for them to control phytoplankton biomass considering their limited ability and slow growth (Ger et al., 2014). Moreover, controlled outlets from water retention facilities were more stochastic than nature seasonality in the distribution of the water temperature, soluble nutrients and discharge values (Abonyi et al., 2012). All these factors combined to suppress the biotic processes, but this benefited diatoms with different life cycles. 


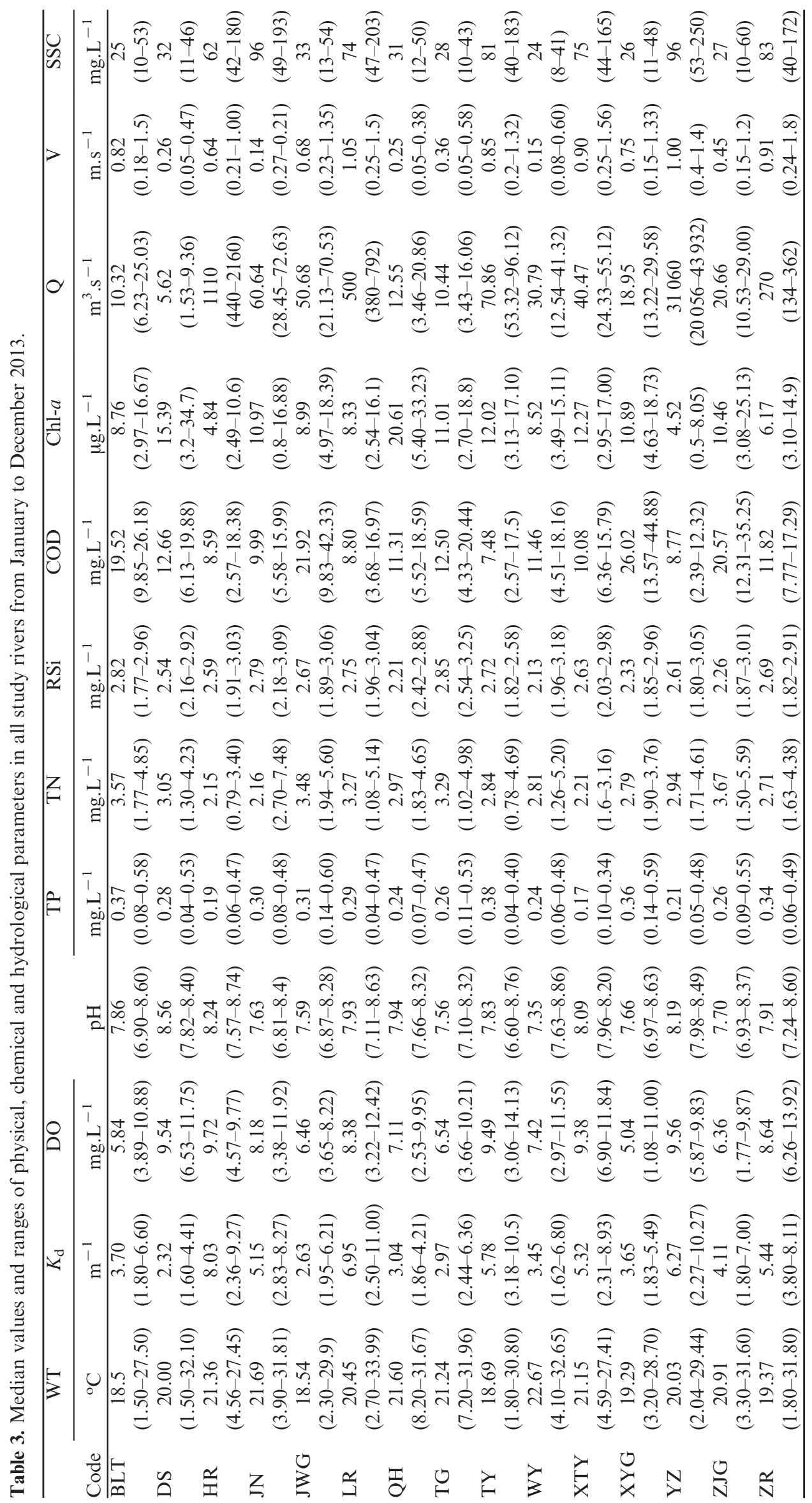



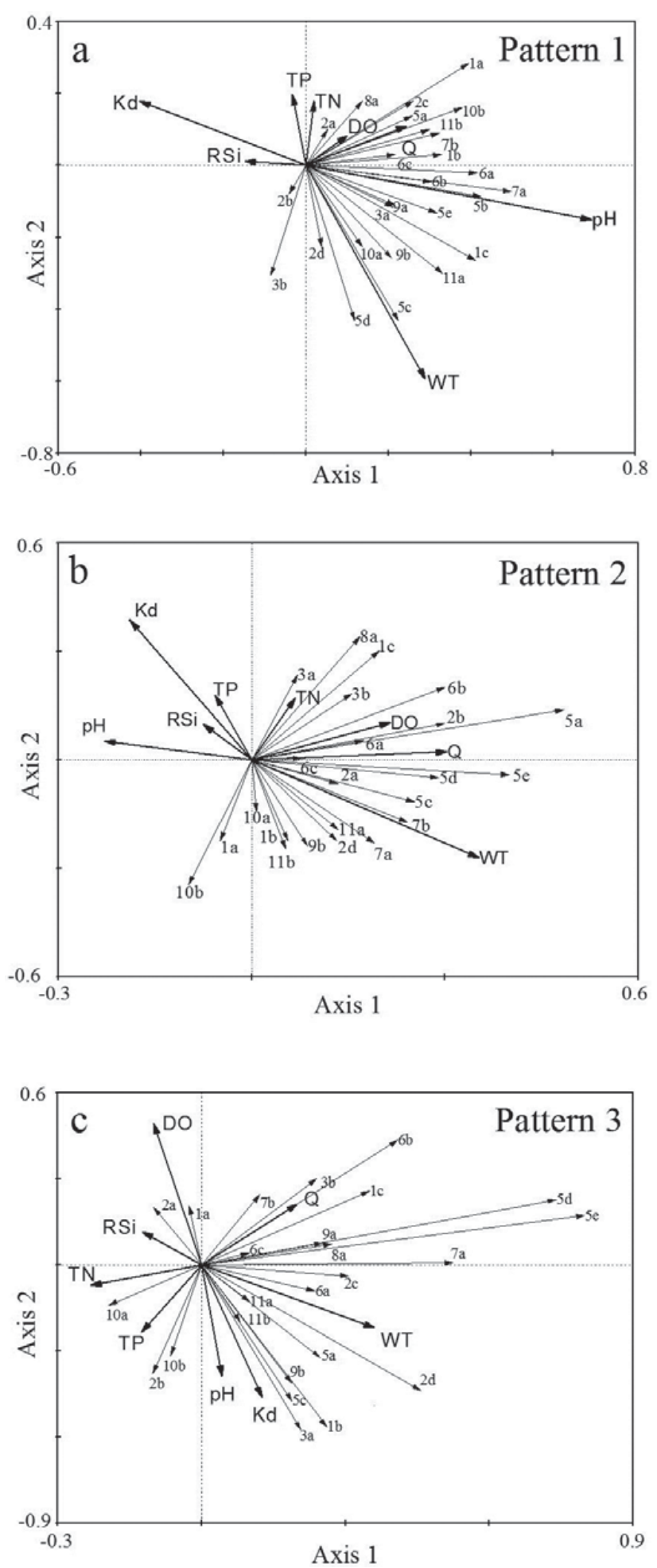

Fig. 8. Biplots of the RDA based on the biomass of MFGs and environmental variables in the rivers of the three patterns: (a) Pattern 1, (b) Pattern 2 and (c) Pattern 3. WT, discharge (Q), DO, RSi, COD, light attenuation coefficient $\left(K_{\mathrm{d}}\right), \mathrm{TN}$ and TP. For short code of MFGs, see Table 2.

Abbreviations: COD, chemical oxygen demand; DO, dissolved oxygen; MFGs, morpho-functional groups; RDA, redundancy analysis; RSi , soluble reactive silica; TN, total nitrogen; TP, total phosphorus; WT, Water temperature.
In Pattern 1, large diatoms, mainly 6a-LargCent (e.g., Stephanodiscus and Aulacoseira) and 6b-LargPenn (e.g., Synedra) often thrived during the six cold months when rotifers dominated. They are better competitors at lower temperature and light, and their relatively high maximum linear dimension might give substantial tolerance to grazing of small zooplankton (Kruk and Segura, 2012). However, it was not clear how these large diatoms with sinking problems and pennates of meroplankton (plankton with a benthic life stage) were successful in low-gradient and slow-flowing rivers. We speculate that this might be related to intensive interference from water retention facilities. First, the eutrophic background met the strong need of large diatoms for silica (Chen et al., 2015). Second, the prolonged residence time supported benthos, epiphyte or meroplankton by increasing dead-zones and light penetrating to the river bed (Butcher, 1932). Third, irregular outlets from water retention facilities led to occasional fast flow and high discharge (Abonyi et al., 2012), which would destroy the equilibrium assemblages and recruit benthos. This type of mixing also helped large diatoms to float (Padisák et al., 2003).

\section{Pattern 2}

Pattern 2 is shaped by intensive navigation. Possibly due to the low gross planktonic production achievable in navigation channels, almost no studies have looked into the effects of intensive navigation on loss processes for phytoplankton, though such effects were recognized long ago (Moss, 1977). In our studied rivers, half of all systems (7/15) belonged to this pattern, because of the fact that navigation is one of the most important uses of rivers for humans. Continual shipping led to high turbidity and extreme chaos in the water habitat, meaning that zooplankton biomass in lotic environments was lower and phytoplankton-zooplankton interactions were weak (Wehr and Descy, 1998). The large quantities of non-living suspended matter or tripton have profound effects on the underwater attenuation of light energy (Reynolds, 1994). Thus, the dominants of Pattern 2 are sufficiently robust true phytoplankton that have the ability to harvest light energy in a turbulent, turbid environment and the capacity for its efficient conversion into new biomass. The high surface-to-volume ratio (e.g., 5a-FilaCyan, 5e-Nostocales, 10a-FilaChlo) and small cell-size or attenuation (e.g., 7a-SmalCent, 7b-SmalPenn) offer quantifiable advantages in terms of metabolism, light reception and entrainment by water currents (Kruk and Segura, 2012).

Rivers of intensive navigation are often deep, which provides unfavorable conditions for meroplankton, especially for those known to produce distinct resting stages (e.g., Aulacoseira and Stephanodiscus of 6a-LargCent). This is because little light can penetrate to the river bed and the productive potential can be realized only close to the water surface (Reynolds and Descy, 1996). 
Massive suspended sediment, high velocity and large discharge all reduced light, but a combination of these may lead to a direct physical impact as well. Besides tolerance to low light, the successful groups of phytoplankton also survived depending on different strategies against the lashing of water flow. The blue-green filaments were flexible to conform to current, and small diatoms had exoskeletal structures as hard armor against the impacts from suspended sediment (Chen et al., 2015). Eutrophication in rivers is likely to express itself in two different forms based on hydraulic residence time (Hilton et al., 2006), and Pattern 2 belonged to the form of shorter retention. In addition, the increase of copepods might be related to their strong ability to break up filaments and break shells (Gliwicz and Pijanowska, 1989).

\section{Pattern 3}

Pattern 3 rivers were characterized by serious organic contamination and high levels of nitrates, which serve as a useful indicator of river eutrophication caused by agriculture and industry (Turner et al., 2003). It is interesting to note that the observed phytoplankton species in these rivers were the most diverse, possibly due to some humaninduced species addition (Abonyi et al., 2012) and a large portion of them possessed flagella (e.g., 2c-SmalEugl, 2d-Crypto). The planktonic production and composition might be substantially dependent upon the input of terrestrial and floodplain primary products (Abonyi et al., 2012).

Also, this pattern seemed particularly suitable for phytoplankton that tolerate low oxygen as well as pollutants. One base of the riverine ecosystem is the balance between algal photosynthesis and respiration (Wehr and Descy, 1998). Often, deep eutrophic rivers are characterized by a net consumption of oxygen (Reynolds and Descy, 1996). The corresponding competition for oxygen is primarily caused by nitrogenous oxygen demand (by nitrification of organic loads) and minor carbonaceous oxygen demand (algal respiration) (Lehman et al., 2004). Pattern 3 rivers, characterized by high TN (Fig. 7), were very low in oxygen due to nitrogenous demand, which led to an oxygen deficit for respiration of a large phytoplankton biomass. Only MFGs of good swimmers with morphological advantages of buoyancy, such as small size (2c-SmalEugl, 2d-Crypto and 7a-SmalCent), flagella (2c-SmalEugl and 2d-Crypto) and gas vesicles or aerotopes (5a-FilaCyan and 5e-Nostocales) could compete well (Reynolds, 2006; Kruk et al., 2010; Kruk and Segura, 2012). Perhaps mixotrophy was a helpful feature (2c-SmalEugl and 2d-Crypto). Also, higher flow velocity, which mixed water with more oxygen favored phytoplankton growth. As in Pattern 2, flushes and impacts were brought in addition, which favored hard diatoms of exoskeletal structures and cyanobacteria of flexible filaments (Chen et al., 2015). All conditions in the rivers of Pattern 3 were harsh to zooplankton life.

\section{Morphological approach}

In this study, the seasonal succession of distinct MFGs defined according to their morphological, physiological and functional attributes can reflect the main features of phytoplankton structures in the investigated rivers, while the taxa approach of genus and class level failed. As our study has shown, on the basis of MFGs, multiple analyses succeeded in clustering three-directional patterns and their controllable factors with threshold values. The MFG approach performed well as an efficient tool for prediction and management of eutrophic environments of plain rivers. However, it seemed that the advantages of applying this approach were conditional.

Previous studies have reported that MFG was not as comprehensive and sensitive as taxa (e.g., Tolotti et al., 2012; Mihaljević et al., 2013). On the other hand, a successful example, like our study, was reported by Gallina et al. (2013) who used MFGs in six peri-Alpine lakes to discover the significant role of increasing spring fertilization and annual water temperature gradients on seasonal phytoplankton development.

We therefore suggested that the key condition for better application of MFG was whole study targets for general laws through matching statistical analysis, rather than detailed problems of a specific water body, whether lakes or rivers. In this way, this may be quite likely for other morphological approaches such as MBFG (Kruk et al., 2010). However, we cannot deny that MFG of phytoplankton compared with taxonomy, need to be improved in explaining environments (Hu et al., 2013), integrating diatoms (Mihaljević et al., 2014) and understanding levels (Abonyi et al., 2014).

\section{Final notes}

Phytoplankton fuel trophic webs and biogeochemical cycling. Anthropogenic influences have driven algal seasonal succession in eutrophic plain rivers to converge to at least three patterns of oriented divergence. It is important to note that our study involved only the most important human activities (dams, navigation and land use), the basic plankton (phytoplankton and zooplankton), and a rather coarse sampling regime (monthly for 1 year). Net population growth of phytoplankton is still sensitive to the time of travel (Reynolds and Descy, 1996), while the connectivity among our studied rivers was out of the scope. Observed data might not necessarily reflect the conditions created by river variability that have affected the phytoplankton (Chen et al., 2015). These limitations are impossible to eliminate thoroughly in field sampling. Perhaps the actual effects of human activity are more profound than expected, especially when dealing with residence time and substance input. It is not possible to predict how long the recovery of a river ecosystem will take or whether the changes are reversible. In any case, the morpho-functional approach or its future derivative will 
become better tools for water monitoring and management because of their appropriate sensitivity.

Acknowledgements. This research was sponsored by the project of the National Natural Science Fund (51279060).

\section{References}

Abonyi A., Leitão M., Lançon A.M. and Padisák J., 2012. Phytoplankton functional groups as indicators of human impacts along the River Loire (France). Hydrobiologia, 698, 233-249.

Abonyi A., Leitão M., Stanković I., Borics G., Várbíró G. and Padisák J., 2014. A large river (River Loire, France) survey to compare phytoplankton functional approaches: do they display river zones in similar ways? Ecol. Indic., 46, 11-22.

Baker K.K. and Baker A.L., 1981. Seasonal succession of the phytoplankton in the upper Mississippi River. Hydrobiologia, 83, 295-301.

Billen G., Garnier J. and Rousseau V., 2005. Nutrient fluxes and water quality in the drainage network of the Scheldt basin over the last 50 years. Hydrobiologia, 540, 47-67.

Butcher R., 1932. Studies in the ecology of rivers. II. The microflora of rivers with special reference to the algae on the river bed. Ann. Botany, 46, 813-861.

Chen N., Liu L., Li Y., Qiao D., Li Y., Zhang Y. and Lv Y., 2015. Morphology-based classification of functional groups for potamoplankton. J. Limnol., 74, 559-571.

Clarke K.R. and Warwick R.M., 2001. Changes in Marine Communities: an Approach to Statistical Analysis and Interpretation (2nd edn), PRIMER-E, Plymouth.

De'ath G. and Fabricius K.E., 2000. Classification and regression trees: a powerful yet simple technique for ecological data analysis. Ecology, 81, 3178-3192.

De Oliveira M.D. and Calheiros D.F., 2000. Flood pulse influence on phytoplankton communities of the south Pantanal floodplain, Brazil. Hydrobiologia, 427, 101-112.

Duarte C.M., Marrasé C., Vaqué D. and Estrada M., 1990. Counting error and the quantitative analysis of phytoplankton communities. J. Plankton Res., 12, 295-304.

Gallina N., Salmaso N., Morabito G. and Beniston M., 2013. Phytoplankton configuration in six deep lakes in the periAlpine region: are the key drivers related to eutrophication and climate? Aquatic Ecol., 47, 177-193.

Gamier J., Billen G. and Coste M., 1995. Seasonal succession of diatoms and Chlorophyceae in the drainage network of the Seine River: observations and modeling. Limnol. Oceanogr, 40, 750-765.

Garnier J., Billen G., Hannon E., Fonbonne S., Videnina Y. and Soulie M., 2002. Modelling the transfer and retention of nutrients in the drainage network of the Danube River. Estuar. Coast. Shelf Sci., 54, 285-308.

Garnier J., Némery J., Billen G. and Théry S., 2005. Nutrient dynamics and control of eutrophication in the Marne River system: modelling the role of exchangeable phosphorus. J. Hydrol., 304, 397-412.

Garrad P.N. and Hey R.D., 1987. Boat traffic, sediment resuspension and turbidity in a Broadland river. J. Hydrol., 95, 289-297.
Ger K.A., Hansson L.A. and Lürling M., 2014. Understanding cyanobacteria-zooplankton interactions in a more eutrophic world. Freshwater Biol., 59, 1783-1798.

Gliwicz Z.M. and Pijanowska J., 1989. The role of predation in zooplankton succession. In: Sommer U. (ed.), Plankton Ecology, Brock/Springer Series in Contemporary Bioscience. Springer, Berlin, Heidelberg, 253-296.

Ha K., Kim H.-W. and Joo G.-J., 1998. The phytoplankton succession in the lower part of hypertrophic Nakdong River (Mulgum), South Korea. Phytoplankton and Trophic Gradients, 129, 217-227.

Ha K., Jang M.-H. and Joo G.-J., 2002. Spatial and temporal dynamics of phytoplankton communities along a regulated river system, the Nakdong River, Korea. Hydrobiologia, 470, 235-245.

Hasle G., 1978. The inverted microscope method. In: Sournia A. (ed.), Phytoplankton Manual. Unesco, Paris, France, 88-96.

Hillebrand H., Dürselen C.D., Kirschtel D., Pollingher U. and Zohary T., 1999. Biovolume calculation for pelagic and benthic microalgae. J. Phycol., 35, 403-424.

Hilton J., O'hare M., Bowes M.J. and Jones J.I., 2006. How green is my river? A new paradigm of eutrophication in rivers. Sci. Total Environ., 365, 66-83.

$\mathrm{Hu}$ R., Han B. and Naselli-Flores L., 2013. Comparing biological classifications of freshwater phytoplankton: a case study from South China. Hydrobiologia, 701, 219-233.

Javornicky P. and Komárková J., 1973. The changes in several parameters of plankton primary productivity in Slapy Reservoir 1960-1967, their mutual correlations and correlations with the main ecological factors.

Kirk J.T.O., 1994. Light and Photosynthesis in Aquatic Ecosystems, Cambridge University Press, Cambridge.

Kiss K., 1994. Trophic level and eutrophication of the River Danube in Hungary. Int. Ver. Theor. Angew. Limnol. Verh., 25, 1688-1691.

Kruk C. and Segura A., 2012. The habitat template of phytoplankton morphology-based functional groups. Hydrobiologia, 698, 191-202.

Kruk C., Huszar V.L., Peeters E.T., Bonilla S., Costa L., Lrling M., Reynolds C.S. and Scheffer M., 2010. A morphological classification capturing functional variation in phytoplankton. Freshwater Biol., 55, 614-627.

Lehman P., Sevier J., Giulianotti J. and Johnson M., 2004. Sources of oxygen demand in the lower San Joaquin River, California. Estuaries, 27, 405-418.

Lepš J. and Šmilauer P., 2003. Multivariate Analysis of Ecological Data Using CANOCO, Cambridge University Press, Cambridge.

Lund J.W.G., Kipling C. and Cren E.D., 1958. The inverted microscope method of estimating algal numbers and the statistical basis of estimations by counting. Hydrobiologia, 11, 143-170.

Mihaljević M., Špoljarić D., Stević F. and Pfeiffer T.Ž., 2013. Assessment of flood-induced changes of phytoplankton along a river-floodplain system using the morpho-functional approach. Environ. Monit. Assess., 185, 8601-8619.

Mihaljević M., Stević F., Špoljarić D. and Pfeiffer T.Ž., 2014. Application of Morpho-Functional Classifications in the evaluation of phytoplankton changes in the Danube River. Acta Zool. Bulg., 66, 153-158.

Moss B., 1977. Conservation problems in the Norfolk Broads and rivers of East Anglia, England - Phytoplankton, 
boats and the causes of turbidity. Biol. Conserv., 12, 95-114.

Naselli-Flores L., Padisák J., Dokulil M.T. and Chorus I., 2003. Equilibrium/steady-state concept in phytoplankton ecology. 502, 395-403.

Padisák J., Soróczki-Pintér E. and Rezner Z., 2003. Sinking properties of some phytoplankton shapes and the relation of form resistance to morphological diversity of plankton - an experimental study. Aquat. Biodiv., 500, 243-257.

Palau A., 2006. Integrated environmental management of current reservoirs and regulated rivers. Limnetica, 25, 287-302.

Reynolds C. and Descy J.-P., 1996. The production, biomass and structure of phytoplankton in large rivers. Large Rivers, 10, 161-187.

Reynolds C.S., 1994. The long, the short and the stalled: on the attributes of phytoplankton selected by physical mixing in lakes and rivers. In: Descy P., Reynolds C. and Padisák J. (eds.), Phytoplankton in Turbid Environments: Rivers and Shallow Lakes, Developments in Hydrobiology, Springer, Netherlands, 9-21.

Reynolds C.S., 1998. What factors influence the species composition of phytoplankton in lakes of different trophic status? Hydrobiologia, 369, 11-26.

Reynolds C.S., 2006. The Ecology of Phytoplankton, Cambridge University Press, Cambridge.

Salmaso N. and Padisák J., 2007. Morpho-Functional Groups and phytoplankton development in two deep lakes (Lake Garda, Italy and Lake Stechlin, Germany). Hydrobiologia, $578,97-112$.
Salmaso N., Naselli-Flores L. and Padisák J., 2012. Impairing the largest and most productive forest on our planet: how do human activities impact phytoplankton? Hydrobiologia, 698, 375-384.

Sommer U., Gliwicz Z.M., Lampert W. and Duncan A., 1986. The PE-model of seasonal succession of planktonic events in fresh waters. Arch. Hydrobiol., 106, 433-471.

Sparks R.E., 1995. Need for ecosystem management of large rivers and their floodplains. BioScience, 45, 168-182.

Tolotti M., Boscaini A. and Salmaso N., 2010. Comparative analysis of phytoplankton patterns in two modified lakes with contrasting hydrological features. Aquat. Sci., 72, 213-226.

Tolotti M., Thies H., Nickus U. and Psenner R., 2012. Temperature modulated effects of nutrients on phytoplankton changes in a mountain lake. Hydrobiologia, 698, 61-75.

Townsend C., 1996. Concepts in river ecology: pattern and process in the catchment hierarchy. Large Rivers, 10, 3-21.

Turner R.E., Rabalais N.N., Justic D. and Dortch Q., 2003. Global patterns of dissolved $\mathrm{N}, \mathrm{P}$ and $\mathrm{Si}$ in large rivers. Biogeochemistry, 64, 297-317.

Wehr J.D. and Descy J.P., 1998. Use of phytoplankton in large river management. J. Phycol., 34, 741-749.

Weithoff G., 2003. The concepts of 'plant functional types' and 'functional diversity' in lake phytoplankton - a new understanding of phytoplankton ecology? Freshwater Biol., 48, 1669-1675. 


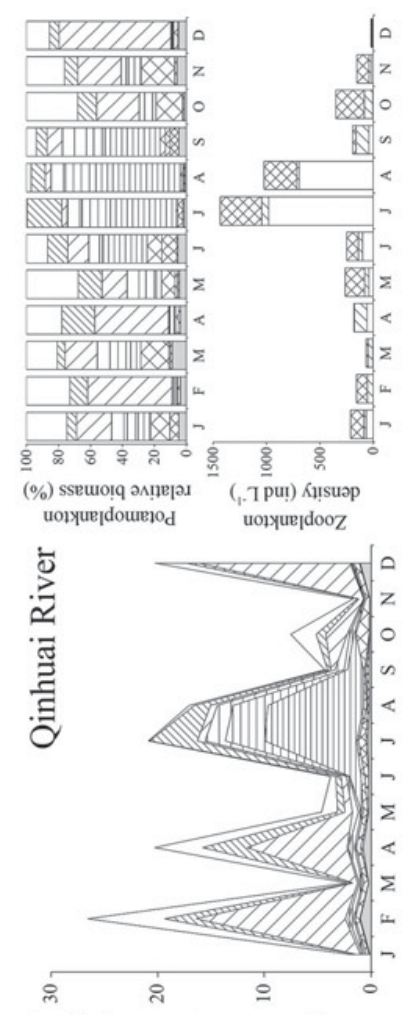

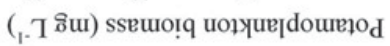
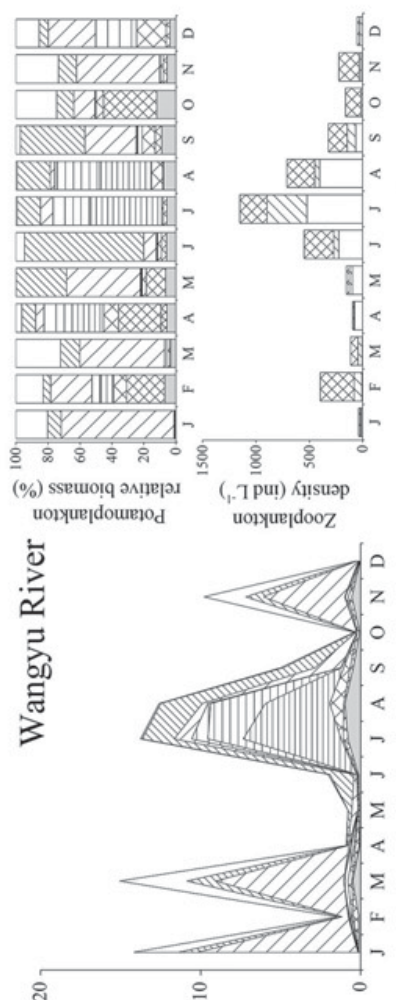

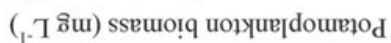
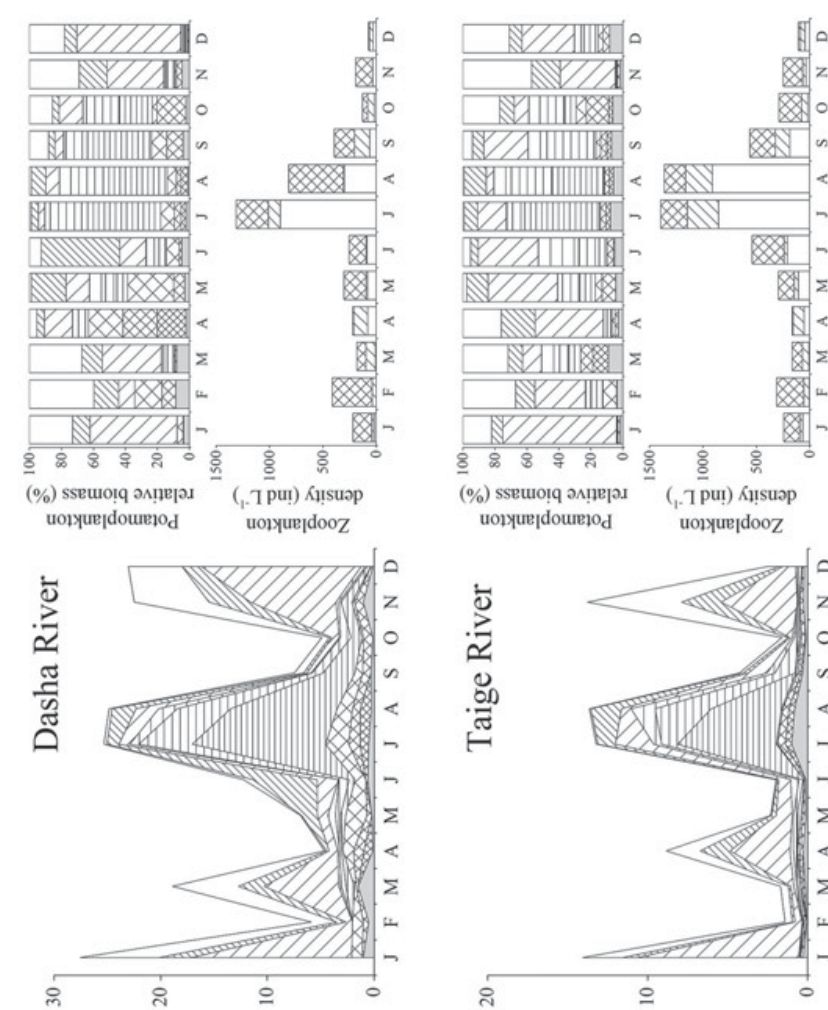

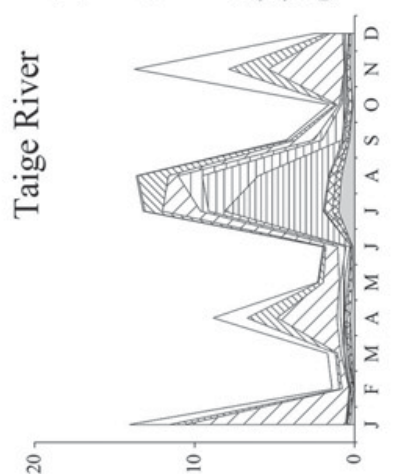

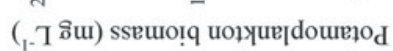
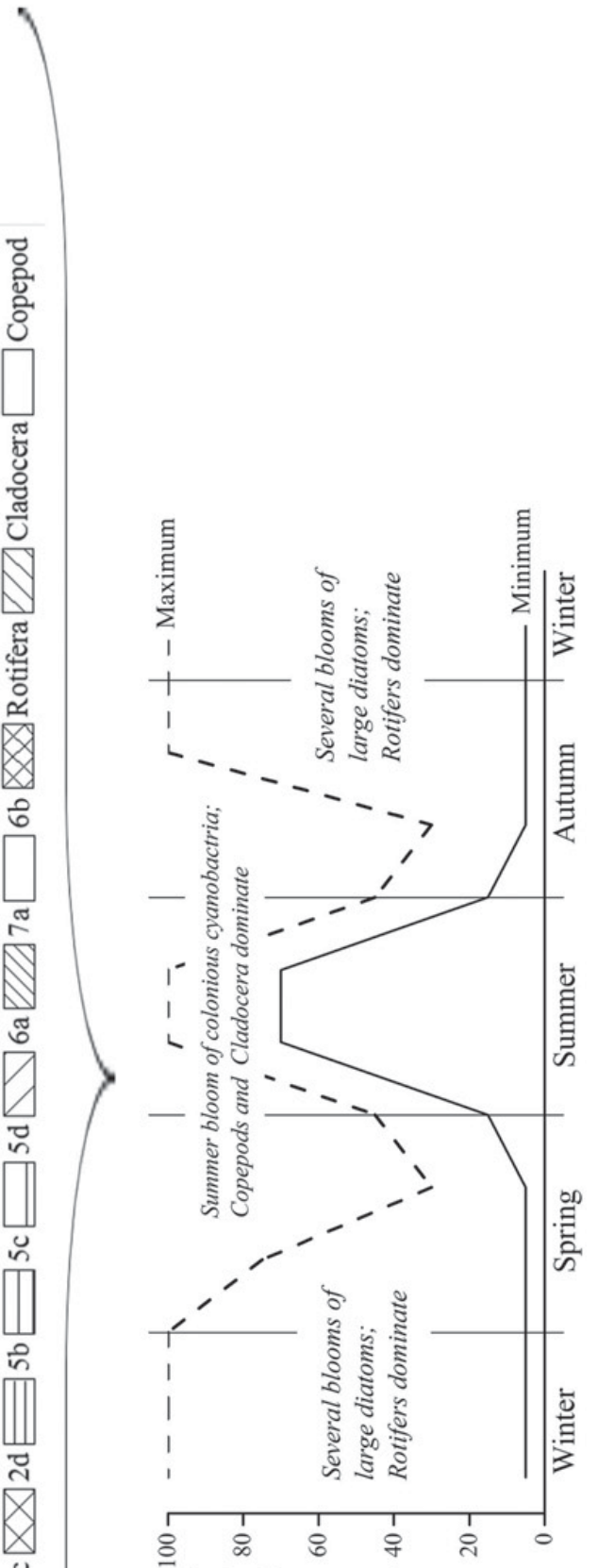

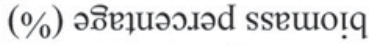

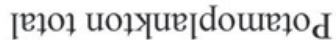



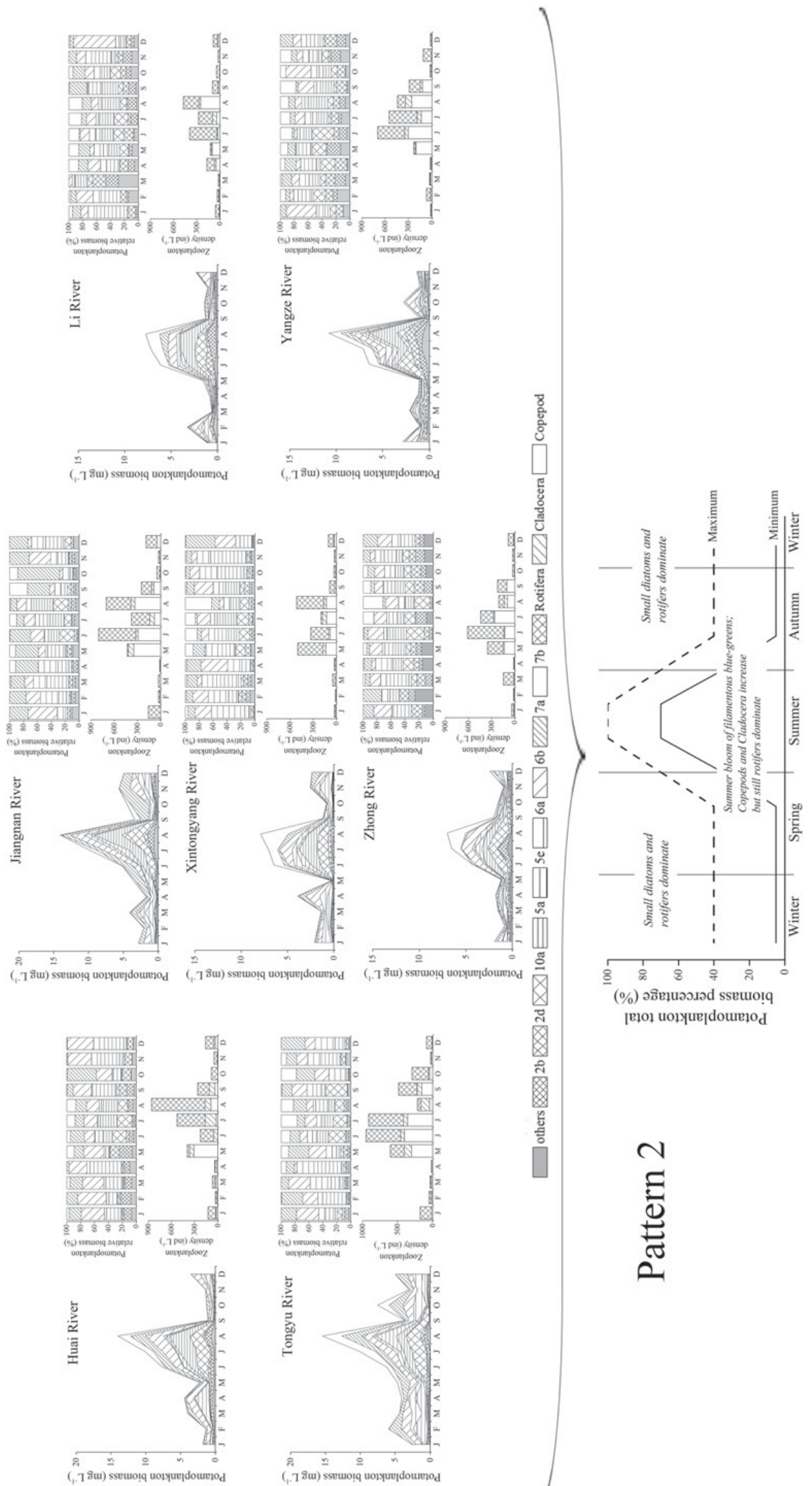


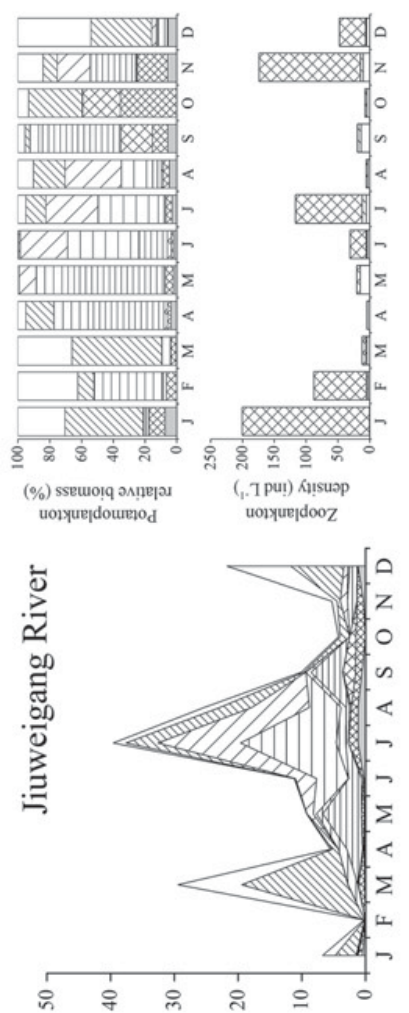

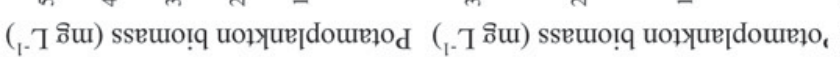

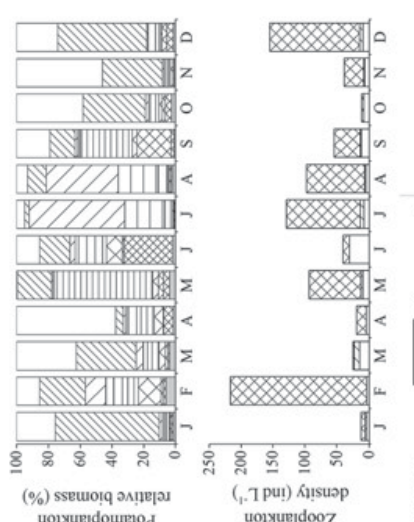

를

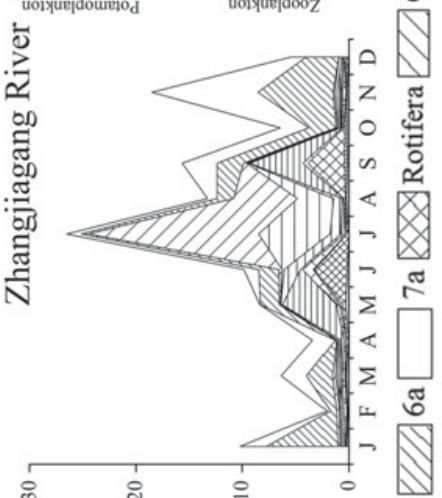

$\stackrel{\circ}{\circ}$
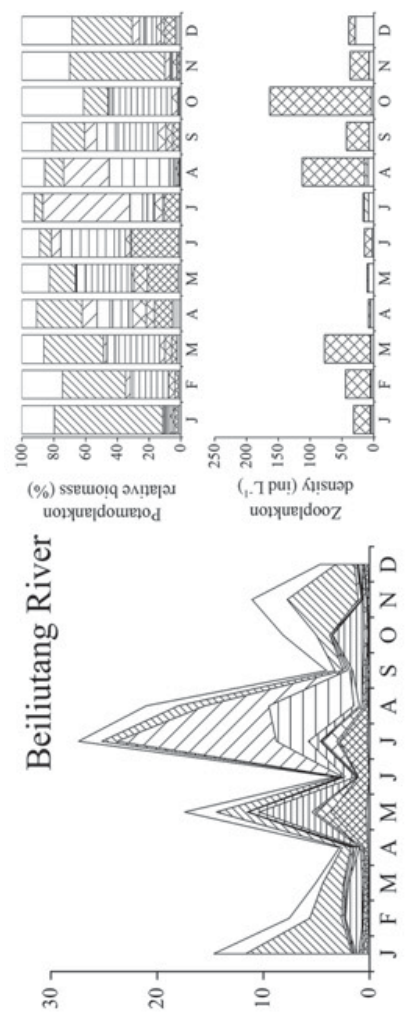

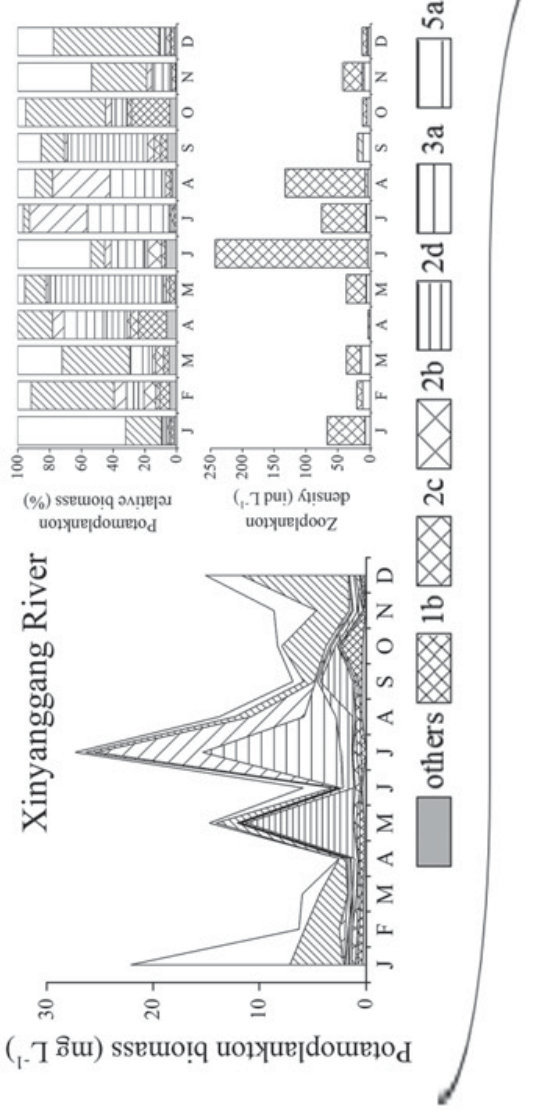

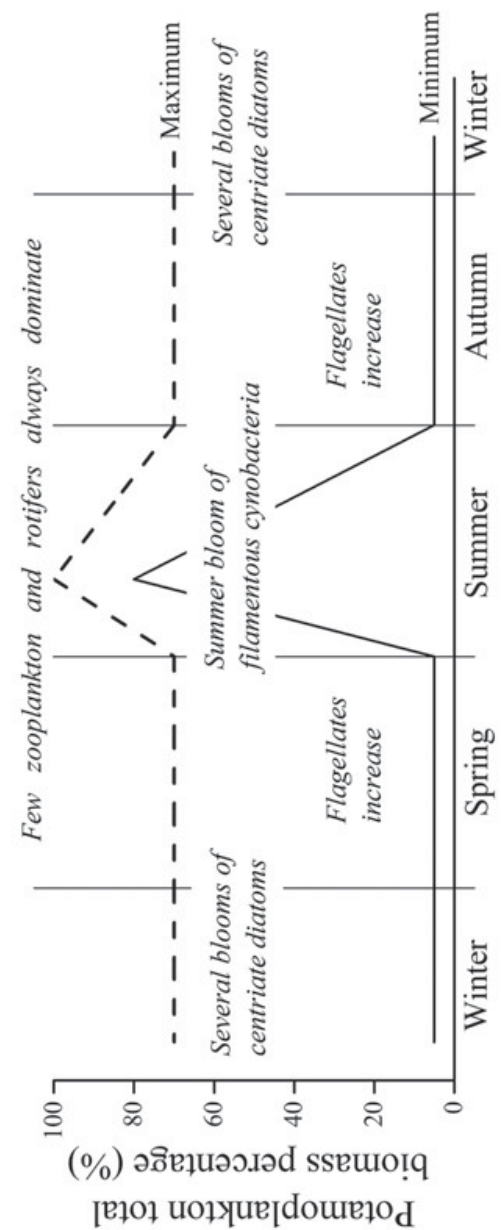

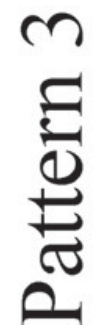

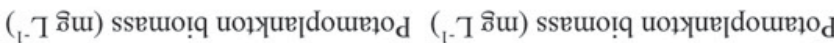

